\title{
Surgery versus intervention in congenital heart disease as a risk factor for executive dysfunction: a case control study
}

\section{Arash Mani}

Shiraz Medical School: Shiraz University of Medical Sciences

Maryam Nasiri

Shiraz Medical School: Shiraz University of Medical Sciences

Hamid Amoozgar ( $\square$ amozgah@sums.ac.ir)

Shiraz Medical School: Shiraz University of Medical Sciences https://orcid.org/0000-0003-3049-5457

Ahmad Ali Amirghofran

Shiraz Medical School: Shiraz University of Medical Sciences

Vahid Nejati

Shahid Beheshti University of Medical Sciences School of Medicine

\section{Research}

Keywords: Behavioral disorder, Congenital heart disease, Executive function, Intervention, Surgery

Posted Date: September 16th, 2021

DOI: https://doi.org/10.21203/rs.3.rs-871738/v1

License: (9) This work is licensed under a Creative Commons Attribution 4.0 International License. Read Full License 


\section{Abstract \\ Background}

Improving surgical and interventional modalities for treating congenital heart disease increased these children's living expectancy, a leading cause of cognitive and behavioral problems. This study compared executive functions among surgically, interventionally treated congenital heart disease, and aged match control.

\section{Methods}

This was a retrospective cross-sectional study. We enrolled thirty children treated with surgery, 30 interventionally treated patients and 30 healthy controls. We compared these participants in the executive functions domains by Stroop test, trail making test, cancellation test, visual and auditory memory span test, and behavioral problems using the parent form strength and difficulty questionnaire. Executive performance in memory span and sustained attention was lower in the surgical group than in the intervention group (Pख0.05).

\section{Results}

Both groups of patients had lower flexibility, memory recall, simple and complex working memory, visual attention, and simple and complex selective attention performance $(P<0.05)$. The effect of behavioral problems on daily life was higher in surgical patients than in the intervention group ( $\mathrm{P} \otimes 0.0001)$. Both groups of patients had higher emotional problems, conduct problems, and communication problems than the normal group (P凶0.0001).

\section{Conclusion}

Interventionaly treated patients had better performance in comparison to surgically-treated patients. Regardless of the severity of the disease or treatment, patients with congenital heart malformations had poor performance compared to normal subjects and suffered from behavioral disorders affecting their daily lives. It is essential to include diagnostic and therapeutic interventions in treating these patients' executive function and behavioral problems.

\section{Introduction}

Congenital heart disease (CHD) is the most common structural congenital disease in children. This disorder is seen in 6 to 13 per 1000 live births. The complexity of CHD is not the same, some of these abnormalities may not impact on person's well-being or even not be recognized for years, but one-third of 
these patients with severe form should be treated in infancy. Today, with advances in surgical and nonsurgical interventions, life expectancy has reached about $80 \%$ in 20 years [1-2].

The most common CHD are ventricular septal defect, atrial septal defect, patent ductus arteriosus, and tetralogy of Fallot [3-4]. In the past three decades, interventional methods have improved in treating these diseases and replaced with surgery which decreased anesthesia and bypass [3]. Unfortunately, children treated are prone to developmental disorders due to prenatal complications such as hypoxia and complications from therapeutic modalities such as decreased blood supply to the brain or stroke [4].

In recent years there have been reports of decreased executive functions and behavioral problems in these children [5-7]. Executive functions (EF) refer to the individual $s$ ' ability to plan their behaviors to achieve a specific goal. EF is the ability to identify problems, provide solutions, and choose the best solution to achieve that goal, and regularly monitor and correct the performance [8].

Most researchers consider the evolution of executive functions as one of the most important achievements of preschool children and regard it as a criterion for predicting successful school performance and child adjustment at school [5]. Self-control requires acquiring a set of cognitive skills that lead to problem solving and behavioral adaptation in new situations. These skills are generally called executive functions. Executive function helps review and monitor actions to perform a task correctly despite multiple triggers [6-7]. Children with executive dysfunction have difficulty achieving educational goals that are not explained with a learning disorder. These children can not apply their knowledge in everyday life [9]. Due to a decline in executive functioning and behavioral problems at school in CHD patients, they need to be screen and rehabilitated.

This study compares executive function and behavioral and emotional problems between successfully surgically and interventionally treated children with CHD without any reported complication and a normal group.

\section{Methods}

This was a cross-sectional study in children aged 8 to 16 years with CHD treated by surgery or catheterization and an aged match normal group.

\section{Sample size and patient selection}

Sixty patients with a history of cardiac problems, 30 in the surgical group and 30 in the interventional group, and 30 normal subjects were enrolled in this study who were treated in affiliated hospital of Shiraz University of Medical Sciences. The patients were randomly selected from the pediatric cardiology and cardiac surgery data bank.

The patients with a complicated surgery or intervention course, any neurological problems, significant motor problems, developmental disabilities, psychiatric problems, learning disorders, or hyperactivity were excluded from the study. All subjects study in ordinary school and had ability in reading and writing. 


\section{Tools}

The researcher calls all patients and invited them for face-to-face interviews. According to the proposed research protocol, all subjects were invited to the research along with one parent. The strengths and difficulties questionnaire (SDQ ), parent version, was completed by the accompanying parent. Stroop test, Trail-making Test (TMT) test, canceling test, auditory and visual memory span test was done for children.

\section{Evaluation of EF}

The executive function is divided into working memory (visual and verbal), cognitive flexibility (the ability of a person to shift attention from one task to another), inhibitory control (the ability not to perform a dominant response but select the appropriate solution to do the job correctly) [12]. The following tests have been used to evaluate these executive functions:

\section{Stroop Test}

This is one of the most commonly used tests for selective attention or focused attention and response inhibition; It is a laboratory model for measuring selective attention [13]. We used this test as a setshifting index.

\section{Trail making test}

Trail-making Test (TMTs) assesses cognitive functioning areas such as processing speed, sequencing, intellectual flexibility, and visual or motor skills [14]. In the present study, the subjects were in the age range of children and adolescents. The graphic form of the test was used instead of the digit forms. The participant should count the points of each circle rather than the numbers. The time required to complete the tests is recorded. This test is used to evaluate simple and complex selective attention.

\section{Cancellation test}

The cancellation test was used as a paper-pencil test to assess visual scanning ability. In this study, a consolation test was used to evaluate the error of deletion (omission) and commotion and the test run time. Based on this, sustained attention capacity, visual search accuracy, and response activation and retention were estimated. [15]. This test is used as a sustained attention index in our study.

\section{Auditory digit Span Test}

The two parts of the sub-test of number span, namely forward and reverse (reverse digits), are separately applicable. This test was used for the evaluation of auditory memory span. In the backward digits, read the subject a series of similar numbers, and each is asked to repeat them in reverse. The reverse digits test was done even if the subject is weak in the forward digits test. This test is used for the evaluation of simple working memory [15]. 
In the third step, the child had to write only the numbers read by the female speaker, and the number of correct rows was compared. This test was used as a hard-working memory index.

\section{Visual Memory Span Test}

Several patterns, from simple to hard, are presented to the subject for four seconds; then, the subject is asked to imitate the pattern observed in the form. In this test, the number of patterns that were painted correctly was compared [30].

\section{Parent SDQ-P questionnaire}

The strengths and difficulties questionnaire (SDQ) is a short screening tool increasingly used to identify children and adolescents' behavioral and emotional problems. This tool is designed to assess five main subtypes of psychiatric symptoms: conduct problems, functionality, emotional symptoms, peer problems, and socially desirable behavior. The first four give the overall score of the problems. The SDQ also has an affective score indicating that the severity of a child's problems is large enough to interfere with his or her daily life [17]. It has been shown that scores obtained from parent and teacher versions of SDQ correlated positively. Comparing scores of performance indices and the overall score of psychiatric diagnostic problems also showed that SDQ is well-validated [19]. The Persian version of the SDQ has good psychometric properties and can be a helpful screening tool for Iranian children with behavioral and emotional problems [18].

\section{Statistical Methods}

In this study, SPSS software version 22 was used. Numerical data were written as mean \pm one standard deviation. Data with normal distribution were statistically evaluated using the T-test statistical method and statistical data with abnormal distribution using the Mann-Whitney $U$ test method. Pearson correlation was used to investigate the statistical relationship between the data. A P-value of less than 0.05 was statistically significant.

\section{Results}

The mean age of subjects was $11.58 \pm 2.45$ in the study, $51.7 \%$ were girls, and $48.3 \%$ were boys. All subjects began primary school education, and they were right-handed.

The arterial septal defect was the most common disease in the intervention group, and single ventricle with total cavo-pulmonary connection was the most common disease in the surgical group.

In the intervention group, 16 atrial septal closures, five ventricular septal defect closures, four ductus closures, three balloon angioplasty of coarctation, one balloon valvuloplasty of aortic stenosis, one pulmonary balloon valvuloplasty were enrolled. 
In the surgical group, 11 patients with total cavo-pulmonary connection, eight repaired tetralogy of Fallot, three atrial septal defect closures, three ventricular septal defect closures, two Rastelli operations, one complete atrioventricular setal defect closure, one transposition of the great artery, one hypertrophic cardiomyopathy with myectomy of the left ventricular outflow tract.

\section{Behavioral Problems Analysis}

There was no significant difference between the two groups of patients in behavioral scores. However, the effect of behavioral problems on the child's life; was significantly higher in the surgical group.

Both patient groups Showed higher scores in emotional symptoms, behavioral problems, communication problems, and lower scores in optimal social behavior, and no difference in overactivity symptoms than the normal group (Table 1).

Table 1

Comparison of the mean of the surgical group and the interven[8]. tion with the normal group in behavioral subscale

\begin{tabular}{|c|c|c|c|c|c|c|}
\hline Variable & intervention & Surgery & Normal & $\begin{array}{l}P \\
\text { between } \\
\text { surgery } \\
\text { and } \\
\text { normal }\end{array}$ & $\begin{array}{l}P \\
\text { between } \\
\text { surgery } \\
\text { and } \\
\text { normal }\end{array}$ & $\begin{array}{l}P \text { between } \\
\text { surgery and } \\
\text { intervention }\end{array}$ \\
\hline Behavioral problems & $3.39 \pm 1.64$ & $\begin{array}{l}3.76 \pm \\
1.83\end{array}$ & $\begin{array}{l}1.76 \pm \\
1.75\end{array}$ & 0.0001 & 0.0001 & 0.269 \\
\hline Emotional symptoms & $3.10 \pm 2.49$ & $\begin{array}{l}4.00 \pm \\
2.86\end{array}$ & $\begin{array}{l}2.25 \pm \\
1.97\end{array}$ & 0.002 & 0.002 & 0.203 \\
\hline ADHD & $4.57 \pm 2.55$ & $\begin{array}{l}4.73 \pm \\
2.67\end{array}$ & $\begin{array}{l}3.99 \pm \\
2.29\end{array}$ & 0.139 & 0.139 & 0.418 \\
\hline $\begin{array}{l}\text { Communication } \\
\text { problems }\end{array}$ & $2.60 \pm 1.83$ & $\begin{array}{l}2.76 \pm \\
1.97\end{array}$ & $\begin{array}{l}1.67 \pm \\
2.04\end{array}$ & 0.005 & 0.005 & 0.667 \\
\hline Optimal behavior & $6.82 \pm 1.88$ & $\begin{array}{l}7.43 \pm \\
1.33\end{array}$ & $\begin{array}{l}8.11 \pm \\
1.75\end{array}$ & 0.009 & 0.009 & 0.216 \\
\hline Total score & $\begin{array}{l}13.67 \pm \\
6.40\end{array}$ & $\begin{array}{l}15.26 \\
\pm 7.29\end{array}$ & $\begin{array}{l}10.05 \\
\pm 5.76\end{array}$ & 0.0001 & 0.0001 & 0.224 \\
\hline $\begin{array}{l}\text { Influence on daily life } \\
\text { from the parents' point } \\
\text { of view }\end{array}$ & $1.57 \pm 0.5$ & $\begin{array}{l}1.53 \pm \\
0.5\end{array}$ & Normal & & & 0.0001 \\
\hline
\end{tabular}

The child's daily life was examined from the parents' point of view. $45 \%$ of parents believed in the influence on one of the areas of family, friendship, school, or leisure activities, and $55 \%$ of parents did not 
believe in this effect (Table 1).

The set-shifting, working memory, visual memory, simple selective attention, and complex selective attention analysis showed no significant difference between the two groups of patients in these fields. However, there was a statistically significant difference with normal (Table 2).

Table 2

Comparison of different areas of executive performance in two groups of patients and each with the norm

\begin{tabular}{|c|c|c|c|c|c|c|}
\hline Variable & Surgery & Intervention & Normal & $\begin{array}{l}\text { P between } \\
\text { surgery and } \\
\text { normal }\end{array}$ & $\begin{array}{l}\text { P between } \\
\text { interventional } \\
\text { and normal }\end{array}$ & $\begin{array}{l}\text { P between } \\
\text { surgery anc } \\
\text { interventior }\end{array}$ \\
\hline Set shifting & $\begin{array}{l}-4.44 \pm \\
5.16\end{array}$ & $-5.92 \pm 4.89$ & 0 & 0.0001 & 0.0001 & 0.272 \\
\hline $\begin{array}{l}\text { Memory } \\
\text { span }\end{array}$ & $\begin{array}{l}2.95 \pm \\
1.27\end{array}$ & $3.46 \pm 1.22$ & 5 & 0.0001 & 0.0001 & 0.037 \\
\hline $\begin{array}{l}\text { Working } \\
\text { memory }\end{array}$ & $\begin{array}{l}1.73 \pm \\
1.27\end{array}$ & $2.17 \pm 1.73$ & 5 & 0.0001 & 0.0001 & 0.181 \\
\hline $\begin{array}{l}\text { Hard work } \\
\text { memory }\end{array}$ & $\begin{array}{l}1.85 \pm \\
1.21\end{array}$ & $2.02 \pm 0.85$ & 5 & 0.0001 & 0.0001 & 0.604 \\
\hline $\begin{array}{l}\text { Visual } \\
\text { memory }\end{array}$ & $\begin{array}{l}2.25 \pm \\
0.90\end{array}$ & $2.35 \pm 1.11$ & 5 & 0.0001 & 0.0001 & 0.722 \\
\hline $\begin{array}{l}\text { Simple } \\
\text { selection } \\
\text { attention }\end{array}$ & $\begin{array}{l}131.12 \\
\pm 64.94\end{array}$ & $108 \pm 52.85$ & 22.93 & 0.0001 & 0.0001 & 0.163 \\
\hline $\begin{array}{l}\text { Complex } \\
\text { Selective } \\
\text { attention }\end{array}$ & $\begin{array}{l}91.00 \\
\pm 38.15\end{array}$ & $\begin{array}{l}122.36 \pm \\
103.23\end{array}$ & 48.97 & 0.0001 & 0.038 & 0.377 \\
\hline
\end{tabular}

Patients in the surgical group had significantly less memory span than the intervention group (catheterization). Also, both groups of patients were significantly lower in memory span than the normal group. (Table 2)

In the sustained attention test, there was a significant difference between the two groups of surgical patients and the intervention in the field of correct selection (correct), omit removal, and omit error. However, there was no difference in the time of the test. In this area, the performance of the norm group was not measured. (Table 3) 
Table 3

Compares the factors of sustained attention between the two groups of patients.

\begin{tabular}{|llll|}
\hline & surgery & Intervention & P-value \\
\hline Correct & $14.8 \pm 4.88$ & $17.23 \pm 2.06$ & 0.0001 \\
\hline Omit & $3.68 \pm 4.08$ & $1.73 \pm 2.06$ & 0.020 \\
\hline Comit & $0.55 \pm 2.40$ & $0.03 \pm 4.08$ & 0.021 \\
\hline Time & $111.73 \pm 42.71$ & $113.16 \pm 49.25$ & 0.628 \\
\hline Omit & $14.8 \pm 4.88$ & $17.23 \pm 2.06$ & 0.0001 \\
\hline
\end{tabular}

\section{Discussion}

Significant advances have been made in the treatment of CHD, either surgically or non-surgically, which led to decreased mortality and increased life expectancy in children with CHD [1-2].

In this regard, we detect more neurodevelopmental disorders in both surgically and interventionaly treated groups, and the most important of that is the low level of cognitive skills [8]. These patients appear to have more impaired memory and task organization. These children also have behavioral disorders in the areas of hyperactivity, impulsivity, conduct, antisocial behavior, isolation, depression, and anxiety [9].

Medical treatment aims are not just to increase life expectancy; quality of life is a priority. Executive dysfunction is an important predictor of academic achievement, social communication, employment, and treatment adherence [19].

Some studies focused on intellectual quotient (I.Q.); Carmen Ryberg et al. examined two groups of congenital heart patients who underwent surgery and catheterization treatments for I.Q. Totally 228 children were classified according to age and severity of the disease. The results showed that $83 \%$ of children with congenital heart disease had expected or even higher intelligence [8]. Low I.Q. was associated with the family's economic level and severity of heart disease. Although intelligence is one of the predictors of a child's performance at school, executive performance also should be considered [8].

J.W.ray et al. compared 45 patients with congenital heart disease who underwent heart surgery with 51 patients who underwent bone marrow transplantation and 51 normal individuals. I.Q. in patients with heart disorders was generally in the normal range, but these patients were less well in data analysis and data processing speed [20]. Chronic illness can be one of the causes of poor performance, but the patients with congenital heart defects were lower in information processing and academic achievement than other chronic diseases [20].

In this study, executive performance has been considered. Also, according to their parents' point of view, children who had been included in this study had a normal I.Q. and no particular need for education. The 
surgically treated patients had lower performance in memory span and sustained attention than the interventional group. The severity of $\mathrm{CHD}$ can explain this difference. The surgical group had more complex CHD (single ventricle, tetralogy of Fallot, aortic coarctation) than the catheterization group (ASD, VSD.PDA).

In some studies, patients with complex CHD have impaired in various areas such as memory, academic status, visual-spatial perception, executive function, and attention [11, 12, 21]. In complex CHD patients, more brain abnormalities have been found in magnetic resonance imaging (MRI), although most of these disorders appear to be acquired, and there is no significant relationship between abnormal findings in MRI and neurodevelopmental tests [22]. Impairment of information processing speed, reaction rate, attention, selective attention, fine movements, working memory, and spatial-visual skills is more common in patients with complex heart abnormalities than patients with simpler abnormalities [10]. A study by Klouda $L$ et al. showed that patients with more severe congenital heart defects had more surgeries associated with more executive dysfunction. The risk of acquired brain injuries during surgery, such as strokes, should also be considered [11]. On the other hand, overprotection, inactivity, parental dependency, and high parental anxiety levels in patients undergoing surgery, especially in cyanotic patients, appear to lead to a lack of cognitive skills. [8]. Patients with severe CHD appear to have a greater risk for congenital brain abnormalities [20], which are also related to physiological events due to fetal and chromosomal abnormalities [23-24]. Also, these patients are exposed to acquired executive dysfunctions due to multiple surgeries, hypoxia during and after surgery, seizures, and physical inactivity [25-26-27]. Complex congenital heart defects can predict neurodevelopmental disorders in adults. Although children with simple congenital anomalies such as atrial septal defect (ASD) also have defects compared to the normal population [28].

In our study, both groups of patients in the areas of attention, set-shifting, memory span, working memory, and visual memory had lower performance.

Some research focused on surgical factors explaining developmental neurological disorders in patients with congenital heart abnormalities [28-29]. Prolonged deep hypothermic circulatory arrest and extracorporeal membrane oxygenation are still considered risk factors for developing neurodevelopmental disorders [28]. Interestingly, complications during surgery can only justify $5-8 \%$ of developmental disorders [30-31]. Despite the advances in surgical procedures, there is no reduction in neurodevelopmental disorders. The nature of the disease, a group of preoperative factors, and factors during surgery are responsible for neurodevelopmental disorders in treated CHD, and surgical treatment does not seem to play a role in improving EF [20].

The present study results also confirm that patients with congenital heart disease, regardless of the type of intervention or the severity of the disease, have a lower performance in executive function than average. However, in the meta-analyzed Petra et al., the executive function in patients with simple heart disease is not significantly different from normal [32]. 
In this study, the SDQ parent questionnaire form was used to assess emotional symptoms, behavioral problems, communication problems, hyperactivity, and desirable behavior and the impact of behavioral disorders on a patient's life [18]. In comparing the two surgical and non-surgical groups, the family reporting about the effect of behavioral disorders on life was significantly higher in the surgical group $(\mathrm{P} \otimes 0.0001)$.

In comparing the patients' group and the normal population, the patients' group had higher scores in emotional symptoms, behavioral problems, and communicational problems than the control group and lower scores in desirable behavior than the control group. There was no difference in the area of hyperactivity in both patients' groups. Similar research suggests that people with chronic illnesses are more prone to behavioral disorders [33-34-35-36]. Also, behavioral and emotional disorders are higher in patients with congenital heart defects than in the normal population, and these disorders are not related to the severity of the disease [37-38].

Kramer. H.H. et al. compared 128 patients with congenital heart disease with 89 normal people in the control group. They found that children with heart disease had more behavioral problems and higher feelings of inferiority and anxiety [39].

In one randomized control trial, Blinger et al. Compared 155 children who underwent arterial switch operation and were in the 4 to 8 age range compared with the control group. The behavioral checklist of parents 'children, Connor's parent scoring scale, and Connor teachers' scoring scale was used in their study. The score for behavioral disorders and children's behavioral checklists, and teacher checklists in the patient group were higher than in the normal group. This study suggests that patients with congenital heart disease are at risk for behavioral disorders [34].

Our study showed more behavioral problems in CHD patients than normal children except attentiondeficit hyperactivity disorder because we exclude these patients from this study.

The analysis of the impact of the above behavioral problems on the child's daily life from the parents' point of view showed that $45 \%$ of parents believe that they have been affected by one of the family domains, school friendships or recreational activities, and $55 \%$ of parents not believe in this. The effect was unbelievably much lower than expected. This issue can be due to more parents' attention to physical illness than behavioral problems, the level of tolerance of the family with the sick child is higher, families refused to express behavioral disorders due to cultural issues, and the participants' average age.

Some studies, including the study of meta-analysis in Norway, which looked at the executive and psychological functioning in children and adolescents with congenital heart disease, had shown that psycho-behavioral disorders appear in older children, and they show more internal disorders such as depression and anxiety than external disorders such as hyperactivity and behavioral problems [32].

\section{Limitation Of Study}


The small number of samples, the high variability of CHD, and lack of information before the operation were the limitation of this study.

\section{Conclusion}

Interventionally treated patients with CHD had better performance than surgically treated patients, and the trend to treat these patients non-surgically can improve these patients' executive function. However, Patients with congenital heart malformations, regardless of the severity of the disease or treatment, had poor performance compared to normal subjects and suffered from behavioral disorders affecting their daily lives. Therefore, it is necessary to include diagnostic and therapeutic interventions in executive performance and behavioral problems in the treatment protocol of these patients. Family education can help faster diagnosis. Disorders of cognitive flexibility can also predict behavioral problems.

\section{Abbreviations}

CHD: Congenital heart disease; EF: Executive functions; SDQ: strengths and difficulties questionnaire; TMT: Trail-making Test; I.Q.: intellectual quotient

\section{Declarations}

\section{Authors' contributions}

AM, MN, HA, AAA and VPN engaged in literature retrieval of the articles, have analyzed the results and wrote the manuscript. MN contributed to wrote the manuscript and discussed on literature analysis. All authors approved the manuscript.

Funding: This work was supported by the vice-chancellor of research at shiraz university of Medical Sciences Grant number 15001.

Ethics approval: The Ethics Committee approved this work at shiraz university of Medical Sciences (IR.sums.med.rec.1396.5251)

Consent to participate: The parents who present in the study completed the informed consent form.

Potential conflict of interest do not exist. Patients' data and questionnaires are availble in the medical records.

The datasets used and analysed during the current study are available from the corresponding author on reasonable request.

\section{Competing interests}

The authors declare that they have no competing interests 


\section{Acknowledgment:}

The data of this study were gathered by Maryam Nasiri as a part of her thesis for the degree of specialty in psychiatry and financially supported by a grant (No: 15001) from Shiraz University of Medical Sciences. The authors thank Maryam Rosta for her kindness in data gathering.

\section{References}

1. Ishikawa T, Iwashima S, Ohishi A, Nakagawa Y, Ohzeki T. Prevalence of congenital heart disease assessed by echocardiography in 2067 consecutive newborns. Acta Paediatr. 2011 Aug;100(8):e5560. https://doi.org/ 10.1111/j.1651-2227.2011.02248.x

2. Khoshnood B, Lelong N, Houyel L, Thieulin AC, Jouannic JM, Magnier S, et al. Prevalence, timing of diagnosis and mortality of newborns with congenital heart defects: a population-based study. Heart. 2012 Nov;98(22):1667-73. https://doi.org/10.1136/heartjnl-2012-302543.

3. Kenny D. Interventional Cardiology for Congenital Heart Disease. Korean Circ J. 2018 May;48(5):35064. https://doi.org/10.4070/kcj.2018.0064.

4. Limperopoulos C, Tworetzky W, McElhinney DB, Newburger JW, Brown DW, Robertson RL Jr, et al. Brain volume and metabolism in fetuses with congenital heart disease: evaluation with quantitative magnetic resonance imaging and spectroscopy. Circulation. 2010 Jan 5;121(Kenny 1):26-33. https://doi.org/10.1161/CIRCULATIONAHA.109.865568

5. Veraksa A, Almazova O, Bukhalenkova D. Studying executive functions in senior preschoolers. Psych J. 2020 Feb;9(1):144-6. https://doi.org/10.1002/pchj.310

6. Nisskaya AK. School readiness outcomes of different preschool educational approaches. Psychol Russia. 2018;11(1): 43-60. https://doi.org/10.11621/pir.2018.0104.

7. Willoughby MT, Kupersmidt JB, Voegler-Lee ME. Is preschool executive function causally related to academic achievement? Child Neuropsychol. 2012;18(1):79-

91. https://doi.org/10.1080/09297049.2011.578572.

8. Ryberg, C., Sunnegårdh, J., Thorson, M., \& Broberg, M. (2016). Intellectual Functioning in Children with Congenital Heart Defects Treated with Surgery or by Catheter Interventions. Frontiers in pediatrics, 4, 113. https://doi.org/10.3389/fped.2016.00113.

9. Calderon J, Bellinger DC. Executive function deficits in congenital heart disease: why is intervention important? Cardiol Young. 2015 Oct;25(7):1238-46. https://doi.org/10.1017/S1047951115001134.

10. Verrall CE, Blue GM, Loughran-Fowlds A, Kasparian N, Gecz J, Walker K, et al. 'Big issues' in neurodevelopment for children and adults with congenital heart disease. Open Heart. $2019 \mathrm{Jul}$ 3;6(2):e000998. https://doi.org/10.1136/openhrt-2018-000998.

11. Klouda L, Franklin WJ, Saraf A, Parekh DR, Schwartz DD. Neurocognitive and executive functioning in adult survivors of congenital heart disease. Congenit Heart Dis. 2017 Jan;12(1):91. https://doi.org/10.1111/chd.12409. 
12. Gerstle M, Beebe DW, Drotar D, Cassedy A, Marino BS. Executive Functioning and School Performance among Pediatric Survivors of Complex Congenital Heart Disease. J Pediatr. 2016 Jun;173:154-9. https://doi.org/10.1016/j.jpeds.2016.01.028.

13. Scarpina Federica, Tagini Sofia: The Stroop Color and Word Test. Frontiers in Psychology.2017;8:557 . https://doi.org/10.3389/fpsyg.2017.00557.

14. Katherine Arbuthnott, Trail Making Test, Part B as a Measure of Executive Control: Validation Using a Set-Switching Paradigm. Journal of Clinical and Experimental Neuropsychology August 2000 ;22(4):518-28. https://doi.org/10.1076/1380-3395(200008)22:4;1-0;FT518.

15. Moses K. Nyongesa,1,Derrick Ssewanyana,1,2 Agnes M. Mutu ,Assessing Executive Function in Adolescence: A Scoping Review of Existing Measures and Their Psychometric Robustness: Frontiers in Psychology. Published online 2019 Mar 1. https://doi.org/10.3389/fpsyg.2019.00311.

16. A. Toornstra, P. P. M. Hurks, W. Van der Elst, G. Kok \& L. M. G. Curfs : Measuring Visual, Spatial, and Visual Spatial Short-Term Memory in Schoolchildren: Studying the Influence of Demographic Factors and Regression-Based Normative DataJournal of Pediatric Neuropsychology volume 5, pages119131(2019). https://doi.org/10.1007/s40817-019-00070-6.

17. Lisanne L Stone, Jan M A M Janssens,Marloes Van Der Maten, Rutger C M E Engels \& Roy Otten. The Strengths and Difficulties Questionnaire: psychometric properties of the parent and teacher version in children aged 4-7. BMC Psychology volume 3, Article number: 4 (2015). https://doi.org/10.1186/s40359-015-0061-8.

18. Tehranidoust M, Shahrivar Z, Pakbaz B, Rezaei A, Ahmadi F. Validity of Farsi Version of Strengths and Difficulties Questionnaire (SDQ). Advances in Cognitive Sciences. 2007; 8 (4) :3339. http://icssjournal.ir/article-1-266-en.html.

19. Calderon J, Angeard N, Moutier S, Plumet MH, Jambaqué I, Bonnet D. Impact of prenatal diagnosis on neurocognitive outcomes in children with transposition of the great arteries. J Pediatr. 2012 Jul;161(1):94-8. https://doi.org/10.1016/j.jpeds.2011.12.036.

20. Wray J, Sensky T. Congenital heart disease and cardiac surgery in childhood: effects on cognitive function and academic ability. Heart. 2001 Jun;85(6):687-

91. https://doi.org/10.1136/heart.85.6.687.

21. Cassidy AR, White MT, DeMaso DR, Newburger JW, Bellinger Executive Function in Children and Adolescents with Critical Cyanotic Congenital Heart Disease. J Int Neuropsychol DC. Soc. 2015 Jan;21(1):34-49. https://doi.org/10.1017/S1355617714001027.

22. Bellinger DC, Wypij D, Rivkin MJ, DeMaso DR, Robertson RL Jr, Dunbar, et al. Adolescents with dtransposition of the great arteries corrected with the arterial switch procedure: neuropsychological assessment and structural brain imaging. Circulation. 2011 Sep 20;124(12):13619. https://doi.org/10.1161/CIRCULATIONAHA.111.026963.

23. Lloyd-Jones D, Adams R, Carnethon M, De Simone G, Ferguson TB, Flegal K, et al. Heart disease and stroke statistics-2009 update: a report from the American Heart Association Statistics Committee 
and Stroke Statistics Subcommittee. Circulation. 2009 Jan 27;119(3):480-6.

https://doi.org/10.1161/CIRCULATIONAHA.108.191259.

24. Canfield MA, Honein MA, Yuskiv N, Xing J, Mai CT, Collins JS, et al. National estimates and race/ethnic-specific variation of selected birth defects in the United States, 1999-2001. Birth Defects Res A Clin Mol Teratol. 2006 Nov;76(11):747-56. https://doi.org/10.1002/bdra.20294.

25. Warnes CA, Liberthson R, Danielson GK, Dore A, Harris L, Hoffman JI, et al. Task force 1: the changing profile of congenital heart disease in adult life. J Am Coll Cardiol. 2001 Apr;37(5):1170-5. https://doi.org/10.1016/s0735-1097(01)01272-4.

26. Mahle WT, Tavani F, Zimmerman RA, Nicolson SC, Galli KK, Gaynor JW, et al. An MRI study of neurological injury before and after congenital heart surgery. Circulation. 2002 Sep 24;106(12 Suppl 1):I109-14. https://doi.org/10.1161/01.cir.0000032908.33237.b1.

27. von Rhein M, Buchmann A, Hagmann C, Huber R, Klaver P, Knirsch W, et al. Brain volumes predict neurodevelopment in adolescents after surgery for congenital heart disease. Brain. 2014 Jan;137(Pt 1):268-76. https://doi.org/10.1093/brain/awt322.

28. Matos SM, Sarmento S, Moreira S, Pereira MM, Quintas J, Peixoto B, et al. Impact of fetal development on neurocognitive performance of adolescents with cyanotic and acyanotic congenital heart disease. Congenit Heart Dis. 2014 Sep-Oct;9(5):373-81. https://doi.org/10.1111/chd.12152.

29. Hoffman GM, Mussatto KA, Brosig CL, Ghanayem NS, Musa N, Fedderly RT, et al. Systemic venous oxygen saturation after the Norwood procedure and childhood neurodevelopmental outcome. J Thorac Cardiovasc Surg. 2005 Oct;130(4):1094-100. https://doi.org/10.1016/j.jtcvs.2005.06.029.

30. Verrall CE, Walker K, Loughran-Fowlds A, et al. Contemporary incidence of stroke (focal infarct and/or haemorrhage) determined by neuroimaging and neurodevelopmental disability at 12 months of age in neonates undergoing cardiac surgery utilizing cardiopulmonary bypasst. Interact Cardiovasc Thorac Surg 2018;26:644-50. https://doi.org/ 10.1093/icvts/ivx375.

31. Hirsch JC, Jacobs ML, Andropoulos D, et al. Protecting the infant brain during cardiac surgery: a systematic review. Ann Thorac Surg2012;94:1365-73. https://doi.org/ 10.1016/j.athoracsur.2012.05.135.

32. Petra A. Karsdorp, MA, Walter Everaerd, PhD, Merel Kindt, PhD, Barbara J.M. Mulder, MD, PhD. Psychological and Cognitive Functioning in Children and Adolescents with Congenital Heart Disease: A Meta-Analysis. Journal of Pediatric Psychology, Volume 32, Issue 5, June 2007, Pages 527541. https://doi.org/10.1093/jpepsy/jsl047.

33. Marino BS, Lipkin PH, Newburger JW, Peacock G, Gerdes M, Gaynor JW, et al. Neurodevelopmental outcomes in children with congenital heart disease: evaluation and management: a scientific statement from the American Heart Association. Circulation. 2012 Aug 28;126(9):114372. https://doi.org/10.1161/CIR.0b013e318265ee8a.

34. . Bellinger DC, Newburger JW, Wypij D, Kuban KC, duPlesssis AJ, Rappaport LA. Behaviour at eight years in children with surgically corrected transposition: The Boston Circulatory Arrest Trial. Cardiol 
Young. 2009 Feb;19(1):86-97. https://doi.org/ 10.1017/S1047951108003454.

35. Sistino JJ, Atz AM, Simpson KN, Ellis C, Ikonomidis JS, Bradley SM. The prevalence of attentiondeficit/hyperactivity disorder following neonatal aortic arch repair. Cardiol Young. 2015 Apr;25(4):663-9. https://doi.org/10.1017/S1047951114000547.

36. Tamera Clancy, Brigid Jordan, Carolina de Weerth \&Frank Muscara. Early Emotional, Behavioural and Social Development of Infants and Young Children with Congenital Heart Disease: A Systematic Review. Journal of Clinical Psychology in Medical Settings volume 27, pages686703(2020). https://doi.org/10.1007/s10880-019-09651-1.

37. Bellinger DC, Wypij D, Rivkin MJ, DeMaso DR, Robertson RL Jr, Dunbar, et al. Adolescents with dtransposition of the great arteries corrected with the arterial switch procedure: neuropsychological assessment and structural brain imaging. Circulation. 2011 Sep 20;124(12):1361-

9. https://doi.org/ 10.1161/CIRCULATIONAHA.111.026963.

38. . Calderon J, Angeard N, Moutier S, Plumet MH, Jambaqué I, Bonnet D. Impact of prenatal diagnosis on neurocognitive outcomes in children with transposition of the great arteries. J Pediatr. 2012 Jul;161(1):94-8. https://doi.org/10.1016/j.jpeds.2011.12.036.

39. Kramer HH, Awiszus D, Sterzel U, van Halteren A, Classen R. Development of personality and intelligence in children with congenital heart disease. J Child Psychol Psychiatry. 1989 Mar;30(2):299-308. https://doi.org/10.1111/j.1469-7610.1989.tb00242.x. 